\title{
Raciocínio não verbal, funções motoras e praxia construtiva em crianças com migrânea: um estudo controlado
}

\author{
Andréa Regina Correa Moutran, Rosely Aparecida Pereira, Leonardo Vaz, \\ Thaís Rodrigues Villa, Deusvenir de Souza Carvalho
}

Setor de Investigação e Tratamento das Cefaleias - Universidade Federal de São Paulo - Unifesp; Instituto de Psicologia Aplicada e Formação Lev Vygostsky

Moutran AR, Pereira RA, Vaz L, Villa TR, Carvalho DS. Raciocínio não verbal, funções motoras, e praxia construtiva em crianças com migrânea: um estudo controlado. Headache Medicine. 2012;3(4):213-4

\section{OBJETIVO}

Comparar o raciocínio não verbal, funções motoras e a praxia construtiva de crianças com migrânea e controles sem cefaléia.

\section{MÉTODO}

Grupo migrânea: 10 crianças de ambos os sexos $(6$ meninas), diagnosticadas segundo os critérios da International Headache Society (ICHD-II, 2004), 6 com 
aura e 4 sem aura, idade entre 8 e 11 anos e 8 meses (10,2 $\pm 1,2$ anos) e com uma média de 8,6 dias de cefaleia /mês (DP $\pm 4,9$ ). Grupo controle: 10 crianças (5 meninas), mesma faixa etária (10,2 $\pm 0,9$ anos) sem história prévia de cefaleia.

Todas as crianças avaliadas são estudantes da rede pública de ensino. Para a avaliação foram utilizados: matrizes progressivas coloridas de Raven (raciocínio não verbal); bateria neuropsicológica Tübinger Luria-Christensen para crianças - TUKI, organizada segundo a teoria relacional sistêmica e dinâmica de Luria avaliando a coordenação global do corpo, função motora das mãos, motricidade fina, praxia oral, regulação verbal do ato motor, sensações cutâneas/sinestésica e estereognosia; teste de figuras complexas de Rey para avaliar a praxia construtiva gráfica e memória imediata visual. Critérios de exclusão: antecedentes mórbidos gestacionais, prematuridade, atraso no desenvolvimento psicomotor, deficiência intelectual, epilepsia, trauma craniano, doenças sistêmicas, meningite, síndromes genéticas, doenças psiquiátricas, uso de medicação profilática para cefaléia ou qualquer outra com efeito no sistema nervoso central. Para todos os participantes foi obtido o consentimento livre e esclarecido dos pais ou responsáveis, além do termo de assentimento da própria criança.

Esse estudo foi aprovado pelo Comitê de Ética em Pesquisa da Universidade Federal de São Paulo. A análise estatística foi realizada por meio do teste te Mann-Whitney sendo considerado significativo $\mathrm{p}<0,05$

\section{RESULTADOS}

grupo migrânea apresentou escores significativamente menores que o grupo controle nas matrizes progressivas coloridas de Raven escore bruto $(p<0,004)$ / percentil $(p<0,001)$; figuras complexas de Rey - cópia $(p<0,016) /$ percentil $(p<0,003)$ e regulação do ato motor $(p<0,012)$ (ver Tabela 1).

\begin{tabular}{lrrrrr}
\multicolumn{5}{l}{ Tabela 1. Comparações entre o grupo controle com o grupo com migrânea } \\
\hline & Grupo Migrânea & \multicolumn{1}{l}{ Grupo Controle } \\
\hline & Média & \multicolumn{1}{c}{ DP } & Média & \multicolumn{1}{c}{ DP } & \multicolumn{1}{c}{ p } \\
\hline Raven/Escore & 25,00 & $\pm 6,41$ & 32,10 & $\pm 1,72$ & $0,004^{*}$ \\
Raven/Percentil & 51,40 & $\pm 25,34$ & 84,00 & $\pm 11,75$ & $0,001^{*}$ \\
Fig Rey tempo (em segundos) & 278,5 & $\pm 46,67$ & 345,6 & $\pm 101,08$ & 0.072 \\
Fig Rey cópia/escore & 21,10 & $\pm 6,49$ & 27,70 & $\pm 4,48$ & $0,016^{*}$ \\
Fig Rey percentil & 6,09 & $\pm 12,68$ & 38,41 & $\pm 27,04$ & $0,003^{*}$ \\
Fig Rey memória imediata/escore & 11,05 & $\pm 5,33$ & 15,10 & $\pm 6,15$ & 0,133 \\
Fig Rey memória imediata/percentil & 21,70 & $\pm 21,92$ & 43,58 & $\pm 27,85$ & 0,066 \\
Função motora global & 10,60 & $\pm 1,34$ & 11,1 & $\pm 0,56$ & 0,499 \\
Função motora das mãos & 28,10 & $\pm 2,02$ & 29,20 & $\pm 1,13$ & 0,162 \\
Praxia oral & 15,50 & $\pm 1,58$ & 16,30 & $\pm 0,82$ & 0,278 \\
Regulação do ato motor & 5,40 & $\pm 0,69$ & 6,0 & $\pm 0,00$ & $0,012^{*}$ \\
Sensações cutâneas sinestésicas & 37,60 & $\pm 1,89$ & 38,40 & $\pm 0,96$ & 0,427 \\
Estereognosia & 9,70 & $\pm 0,67$ & 9,80 & $\pm 0,42$ & 0,913 \\
\hline
\end{tabular}

\section{CONCLUSÃO}

Crianças com migrânea quando comparadas aos controles apresentaram pior desempenho em testes de raciocínio não verbal, dificuldades na organização e integração perceptomotora, ou seja, na praxia construtiva gráfica, além de se mostrarem menos eficiente na regulação do ato motor, tarefa esta que está relacionada ao funcionamento executivo e o processo atencional.

Desta forma, estes déficits podem gerar um impacto negativo tanto no desempenho escolar, quanto nas atividades cotidianas da criança.

\section{REFERÊNCIAS}

1. Headache Classification Subcommittee of the International Headache Society The international classification of headache disorders; 2nd edition. Cephalalgia.2004; 24(suppl 1): 9-160;

2. Deegener G, Dietel B, Kassel H, Matthaei R, Nödl H. Neuropsychologische Diagnostik bei Kindern und Jugendlichen: Handbuch zur TÜKKI - Tübinger Luria-Christensen neuropsychologische für kinder. Weinheim:Psychologie-Verlags-Union; 1992

3. Angelini AL, Alves IRC, Custódio E M, Duarte WF, Duarte JLM. Manual Matrizes Progressivas Coloridas de Raven: escala especial. Centro Editor de Testes e Pesquisas em Psicologia, São Paulo, 1999.

4. Oliveira, MS. Figuras Complexas de Rey: teste de cópia e de reprodução de memória de figuras geométricas. Casa do Psicólogo, São Paulo, 2010. 